\title{
Perancangan Unit Instalasi Pengolahan Air Minum Kampus Institut Teknologi Sepuluh Nopember
}

\author{
Eko Ary Priambodo dan Hariwiko Indaryanto \\ Jurusan Teknik Lingkungan, Fakultas Teknik Sipil dan Perencanaan, Institut Teknologi Sepuluh Nopember (ITS) \\ Jl. Arief Rahman Hakim, Surabaya 60111 Indonesia \\ e-mail: hwi_corp@yahoo.com
}

\begin{abstract}
Abstrak-Menurut masterplan Kampus Institut Teknologi Sepuluh Nopember (ITS) akan memiliki jumlah civitas akademik 25.000 orang dengan kebutuhan air minum sebesar $17 \mathrm{l} /$ detik, sedangkan tinggi hujan rata-rata di wilayah Kampus ITS seluas 187 ha tersebut adalah $2.065 \mathrm{~mm}$ per tahun. Dengan demikian Kampus ITS memiliki potensi dalam pemanfaatan air hujan untuk memenuhi kebutuhan air minum. Dalam rangka pemenuhan kebutuhan air minum secara mandiri dan mengurangi anggaran biaya penyediaan air minum maka diperlukan perencanaan unit bangunan pengolahan air minum Kampus ITS. Berdasarkan penelitian pendahuluan didapatkan air baku yang berasal dari limpasan air hujan memenuhi standar kualitas air baku kelas 2. Lokasi IPAM direncanakan berada pada lahan seluas $1.927 \mathrm{~m}^{2}$ di Jalan Teknik Mesin Kampus ITS dan akan dibangun 3 unit IPAM di lokasi tersebut. Sedangkan lokasi kolam penampungan air baku memiliki luas $4.458 \mathrm{~m}^{2}$ dengan kedalaman 4-5 $\mathrm{m}$ yang berada $442 \mathrm{~m}$ dari lokasi IPAM. Pembangunan IPAM Kampus ITS akan direncanakan dalam 3 tahap pembangunan. Pada tahap 1 memiliki kapasitas produksi sebesar 6,5 1/detik. Unit-unit yang digunakan dalam IPAM Kampus ITS adalah intake, koagulasi, flokulasi, sedimentasi, filtrasi, desinfeksi, reservoir dan rumah pompa.
\end{abstract}

Kata Kunci-air limpasan hujan, air minum, biaya, kampus its, pengolahan air minum

\section{PENDAHULUAN}

$\mathrm{K}$ AMPUS Institut Teknologi Sepuluh Nopember (ITS) memiliki luas sebesar \pm 187 ha yang terletak pada ketinggian berkisar antara 3-4 mdpl. Tahun 2015 jumlah civitas akademik Kampus ITS 21.492 orang [1]. Dalam memenuhi kebutuhan air minum Kampus ITS masih mengandalkan 100\% suplai dari PDAM Surabaya dengan biaya pengeluaran sebesar Rp. 259.332.416 per bulan pada tahun 2015 [2]. Masterplan Kampus ITS direncanakan dapat menampung 25.000 civitas akademik dengan kebutuhan air 17 1/detik.[4] Kampus ITS memiliki tinggi hujan $2.065 \mathrm{~mm} /$ tahun [3], dengan tinggi hujan tersebut Kampus ITS memiliki potensi dalam pemanfaatan air hujan untuk mencukupi kebutuhan air minum. Pemanfaatan air hujan sudah didukung dengan terbangunnya kolam penampung buatan sejumlah delapan buah kolam yang terletak di beberapa titik di dalam wilayah ITS Kolam penampung ini berfungsi sebagai tempat penampungan air hujan, sehingga dapat dimanfaatkan di waktu musim kemarau. Kawasan Kampus ITS dibatasi dengan sungai yang menghubungkan kolam penampung satu dengan lainnya sehingga air dapat terdistribusi secara merata ke kolam penampung. Penyediaan air minum dengan air baku kolam penampung Kampus ITS diperlukan unit-unit pengolahan terlebih dahulu untuk memenuhi baku mutu air minum yang tertera pada PERMENKES no.492 tahun 2010 [5].

Faktor yang memengaruhi pemilihan unit pengolahan salah satunya karakteristik air baku, sehingga diperlukan analisis air kolam penampung Kampus ITS sebagai air baku. Pemilihan unit pengolahan yang tepat dan efisien diharapkan dapat mengurangi biaya pengeluaran Kampus ITS untuk penyediaan air minum.

\section{METODOLOGI PERANCANGAN}

\section{A. Kerangka Perancangan}

Rangkaian kegiatan perancangan yang terdapat dalam kerangka perancangan dapat diuraikan sebagai berikut:

1) Ide studi

Ide penyusunan penelitian ini adalah merencanakan unit pengolahan air minum di Kampus ITS untuk mengurangi biaya pengeluaran Kampus ITS dalam hal penyediaan air minum. Dengan latar belakang tersedianya sumber air baku berupa air kolam penampung di dalam Kampus ITS.

2) Studi literatur

Studi literatur merupakan tinjauan pustaka sebagai kegiatan mengumpulkan informasi yang berguna, memahami konsep perancangan dan mendapatkan data penunjang untuk kegiatan perancangan yang berasal dari literatur. Tinjauan pustaka yang dilakukan meliputi baku mutu air baku, air minum yang di gunakan di Indonesia dan unit-unit pengolahan air minum.

3) Pengumpulan data

Data yang di gunakan dalam perancangan unit bangunan pengolahan air minum Kampus ITS ini antara lain:

a. Data Sekunder

Data sekunder yang di perlukan dalam kegiatan perancangan, antara lain:

- Data tinggi hujan yang diperoleh dari BMKG kota surabaya, digunakan untuk mengetahui potensi air hujan yang dapat dimanfaatkan.

- Data jumlah civitas akademik Kampus ITS yang diperoleh dari birokrasi Kampus ITS, digunakan untuk proyeksi kebutuhan air.

- Data kebutuhan air Kampus ITS yang diperoleh dari rekening tagihan air Kamus ITS yang dikeluarkan oleh PDAM kota Surabaya, digunakan untuk menentukan debit unit pengolahan air minum.

- Masterplan Kampus ITS yang diperoleh dari birokrasi Kampus ITS, digunakan untuk menentukan letak unit 
pengolahan.

b. Data Primer

Data primer yang diperlukan dalam kegiatan perancangan, antara lain:

- Kondisi eksisting lokasi perancangan untuk mengetahui kondisi terbaru lokasi perancangan.

- Harga bahan struktur, mekanical dan listrik untuk menganalisis kelayakan ekonomi.

5) Perancangan unit-unit pengolahan

Pengembangan unit-unit pengolahan ini dilakukan berdasarkan beberapa pertimbangan yang meliputi tata guna lahan, pengamatan kondisi lapangan yang ada dan hasil analisis data yang mengacu pada parameter standar kualitas air minum yang digunakan di Indonesia, yaitu Permenkes RI Nomor 492/Menkes/Per/IV/2010 tentang Persyaratan Kualitas Air Minum, sehingga didapatkan unit pengolahan yang tepat dan efisien dalam pengolahannya. Perancangan pengembangan ini sendiri, diupayakan untuk tidak mengubah kondisi eksisting yang telah ada. Hal tersebut dikarenakan pertimbangan teknis dan juga ekonomi.

\section{HASIL DAN PEMBAHASAN}

\section{A. Lokasi Perencanaan}

Lokasi IPAM direncanakan berada pada lahan seluas 1.927 $\mathrm{m}^{2}$ di Jalan Teknik Mesin Kampus ITS dan akan dibangun 3 unit IPAM di lokasi tersebut. Sedangkan lokasi kolam penampungan air baku memiliki luas $4.458 \mathrm{~m}^{2}$ dengan kedalaman 4-5 m yang berada $442 \mathrm{~m}$ dari lokasi IPAM.

\section{B. Perencanaan Unit IPAM}

Perancangan IPAM ITS akan direncanakan dalam 3 tahap pembangunan dengan kapasitas total 17 1/detik. Pada tahap 1 akan dibangun dengan kapasitas 6,5 L/detik. Tahapan pengolahan yang akan digunakan sebagai berikut:

- Tahap pertama koagulasi \& flokulasi

Air baku dengan kekeruhan 5,97 NTU dan TSS 42,1 mg/L dapat di turunkan secara efektif dengan koagulasi \& flokulasi untuk membentuk flok.

- Tahap ke dua sedimentasi

Tahap untuk memisahkan partikel flok yang telah terbentuk.

- Tahap ke empat filtrasi Tahapan untuk memisahkan partikel yang masih lolos dalam proses pengendapan.

- Tahap ke lima desinfeksi Tahapan untuk mematikan mikroorganisme yang masih terkandung dalam air olahan

Skema unit pengolahan dapat di lihat pada Gambar 1.

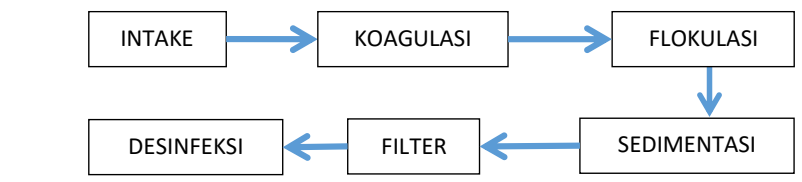

Gambar 1. Skema Unit Pengolahan Air Kampus ITS

1) Perencanaan Unit Intake Intake ini akan menggunakan pipa fleksibel dan ponton sebagai pendukung sistem penyadapan air baku. Penggunaan pipa fleksibel dan ponton ini bertujuan untuk mengatur elevasi pipa sadap secara otomatis sehingga didapatkan kualitas air yang bagus dan akan mempermudah dalam pengoperasiannya.

Direncanakan:

\begin{tabular}{lll}
\hline & Debit (Q) & $: 17$ 1/detik \\
- & Panjang pipa sadap $: 15 \mathrm{~m}$ \\
- & Panjang pipa pembawa: $442 \mathrm{~m}$
\end{tabular}

Perhitungan:

- Pipa sadap

Digunakan pipa di pasaran berdiameter $125 \mathrm{~mm}$ (5 inch)

Hf $=\frac{L}{\left(0,00155 \times C \times D^{2,63}\right)^{1,85}} \times Q^{1,85}=0,34 m$

- Pipa pembawa berdiameter $125 \mathrm{~mm}$ (5 inch)

Hf $=1,5 \mathrm{~m}$

- Pompa Intake

Pompa intake digunakan 2 unit pompa yang bekerja secara bergantian. Perhitungan head pompa sebagai berikut:

$\mathrm{H}$ pompa $=\mathrm{Hf}+\mathrm{H}_{\text {intake }}+\mathrm{H}_{I P A}+$ Sisa tekan=13,6 $\mathrm{m}$

Pada tahap perencanaan ini pompa intake hanya untuk memenuhi kebutuhan 1 unit IPA dengan debit 6,5 1/detik. Maka spesifikasi pompa yang $\mathrm{Q}=6,5 \mathrm{l} /$ detik dan Head $=13,6 \mathrm{~m}$. Desain unit intake dapat dilihat pada Gambar 2.

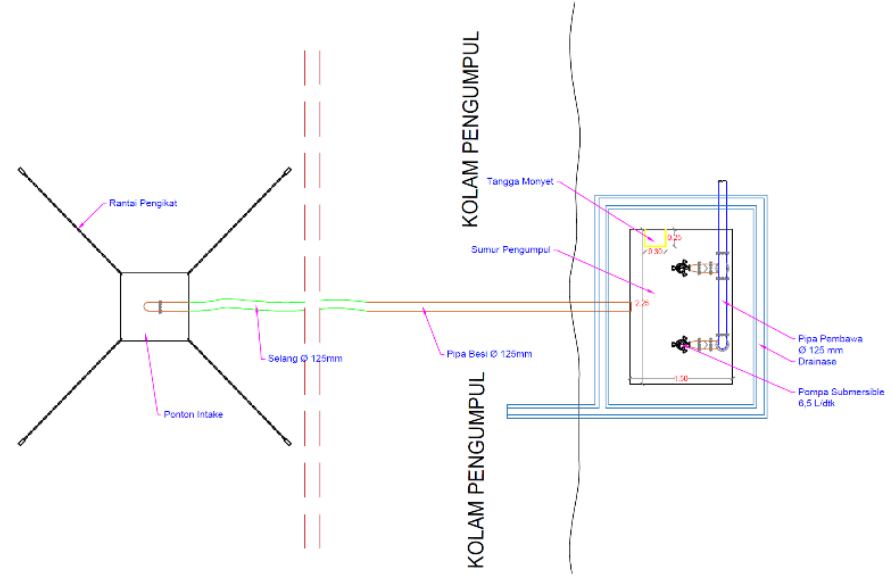

Gambar 2. Desain Unit Intake

\section{2) Perencanaan Unit Koagulasi}

Koagulasi berfungsi sebagai pengaduk koagulan secara merata dan pembentuk inti flok. Unit koagulasi direncanakan dengan sistem koagulasi hidrolik yang berupa koagulasi dalam pipa. Koagulasi dalam pipa memanfaatkan head pompa sehingga tidak di perlukan jatuhkan yang terlalu tinggi dan lebih efektif dalam koagulasi.

Direncanakan:

- Debit : $6,5 \mathrm{l} /$ detik

- Waktu detensi (td) : 20 detik

- Diameter pipa : $100 \mathrm{~mm}$

- Tinggi pipa tegak : $4 \mathrm{~m}$

Perhitungan:

- Volume pipa injeksi $=0,063 \mathrm{~m}^{3}$

- Td pipa injeksi =3,7 detik

- G koagulasi pipa $=\sqrt{\frac{\text { gxh }}{v \times t d}}=3.470 /$ detik

- Nilai G.Td = $=12.842$ 
- Tinggi jatuhkan $=\frac{\mathrm{G}^{2} \times \mathrm{v} \times \mathrm{td}}{\mathrm{g}}=0,16 \mathrm{~m}$

Berdasarkan uji laboratorium dosis alum yang digunakan sebagai koagulan sebesar $4 \mathrm{mg} / \mathrm{L}$. Koagulan akan di injeksikan dalam pipa air baku dengan menggunakan pipa pembawa koagulan. Injeksi koagulan ini memanfaatkan ruang kosong akibat perubahan dimensi pada pipa sehingga tekanan di titik tersebut

\section{3) Perencanaan Unit Flokulasi}

Flokulasi berfungsi untuk memperbesar inti flok yang telah terbentuk ada unit koagulasi. Flokulasi direncanakan dengan sistem hidrolik dengan memanfaatkan beda elevasi pada unit yang akan didesain. Pemilihan sistem hidrolik didasarkan pada mudahnya dalam operasional dan tidak memerlukan energi tambahan. Bentuk unit flokulasi direncanakan berbentuk segieman sejumlah 2 unit dengan 6 kompartemen setiap unit.

Direncanakan:

- Kedalaman air (h) : 2,5 m

- Jumlah flokulator : 2 unit

- Koefisien belokan (K) : 0,8

- Td total :480 detik

- Kompartemen : 6 buah

- Flokulator berbentuk persegi enam

- G Kompartemen I : 75 detik $^{-1}$

- G Kompartemen II : 60 detik $^{-1}$

- G Kompartemen III : 40 detik $^{-1}$

- G Kompartemen IV : 30 detik $^{-1}$

- G Kompartemen V : 20 detik $^{-1}$

- G Kompartemen VI : 10 detik $^{-1}$

Perhitungan:

- Q per bangunan $=0,00325 \mathrm{~m}^{3} /$ detik

- Vol. total bak $=1,95 \mathrm{~m}^{3}$

- Vol kompartemen $=0,325 \mathrm{~m}^{3}$

- Panjang sisi $(\mathrm{S})=\sqrt{\frac{2}{3} \frac{\mathrm{V}}{\sqrt{3} \cdot \mathrm{H}}}=0,2 \mathrm{~m}$

- Td tiap bak = 80,74detik

- Luas penampang $=\frac{3}{2} S^{2} \sqrt{3}=0,1 \mathrm{~m}^{2}$

- Kecepatan aliran $=0,031 \frac{\mathrm{m}}{\text { detik }}$

- Headloss yang diperlukan untuk memenuhi G rencana

$\mathrm{Hf}=\frac{\mathrm{G}^{2} \mathrm{x} \cup \mathrm{xtd}}{\mathrm{g}}$

$\mathrm{G} 1=75 /$ detik

$\mathrm{Hf}=0,041 \mathrm{~m}$

$\mathrm{G} 2=60 /$ detik

Hf $=0,026 \mathrm{~m}$

$\mathrm{G} 3=40 /$ detik

$\mathrm{Hf}=0,012 \mathrm{~m}$

$\mathrm{G} 4=30 /$ detik

$\mathrm{Hf}=0,007 \mathrm{~m}$

$\mathrm{G} 5=20 /$ detik

$\mathrm{Hf}=0,003 \mathrm{~m}$

G6 $=10 /$ detik

$\mathrm{Hf}=0,001 \mathrm{~m}$

Direncanakan saluran penghubung antar kompartemen berbentuk persegi perencanaan dimensi berbeda tiap kompartemen yang mengacu pada headloss tiap kompartemen.

$$
\begin{array}{ll}
\mathrm{Hf}=\mathrm{K} \frac{\mathrm{V}^{2}}{2 \cdot \mathrm{g}} & \text { (Persamaan headloss) [6] } \\
\mathrm{V}=\mathrm{Q} / \mathrm{A} & \text { (Persamaan luas penampang) } \\
\mathrm{S}=\sqrt{\mathrm{A}} & \text { (Persamaan luas persegi) }
\end{array}
$$

Panjang sisi $(S)=\sqrt{\frac{Q}{\sqrt{\frac{\mathrm{Hfx2g}}{\mathrm{K}}}}}$

Nilai K yang di gunakan adalah $\mathrm{K}$ untuk perubahan dimensi saluran $(\mathrm{K}=1)$ dan $\mathrm{K}$ untuk belokan $90^{\circ}(\mathrm{K}=0,16)$

Saluran 1 ke $2=0,12 \mathrm{~m}$

Saluran 2 ke $3=0,15 \mathrm{~m}$

Saluran 3 ke $4=0,17 \mathrm{~m}$

Saluran 4 ke $5=0,20 \mathrm{~m}$

Saluran 5 ke $6=0,25 \mathrm{~m}$

\section{4) Perencanaan Unit Sedimentasi}

Sedimentasi berfungsi untuk mengendapkan partikel flok yang telah terbentuk pada proses koagulasi dan flokulasi. Sedimentasi didesain menggunakan plate settler dengan spesifikasi sebagai berikut:

- Jarak plate settler (w) : :7,5 cm

- Tinggi plate settler (h) : $1,73 \mathrm{~m}$

- Tebal plate settler : $1 \mathrm{~mm}$

- Sudut plate settler $(\theta): 60^{\circ}$

Plate settler berfungsi untuk memperluas zona pengendapan dan memperpendek jarak pengendapan sehingga proses pengendapan efektif terjadi di plate settler. Aliran di sedimentasi ini merupakan aliran downflow yang terjadi pada zona inlet dan upflow yang terjadi di plate settler. Menggunakan imhoff cone pada uji laboratorium didapatkan:

- Kecepatan pengendapan $(\mathrm{Vs})=0,0002 \mathrm{~m} / \mathrm{detik}$

Perhitungan Plate Settler

Direncanakan :

- Jumlah unit: 2 unit

- Q tiap unit : $0.00325 \mathrm{~m}^{3} /$ detik

- Lebar : Menyesuaikan lebar total flokulasi

- Nfr $\quad:>10^{-5}$ (tidak terjadi aliran pendek)

- Nre $\quad:<2000$ ( tidak terjadi aliran turbulen)

- Platte ke ruang lumpur : $40 \mathrm{~cm}$

- Platte ke gutter : $15 \mathrm{~cm}$

Perhitungan :

- $\operatorname{Luas}(\mathrm{A})$

$$
=\frac{\mathrm{Q}}{\mathrm{Vs}} \times \frac{\mathrm{w}}{\mathrm{h} \cos \alpha+\mathrm{w} \cos ^{2} \alpha}[7]
$$

$$
=1,91 \mathrm{~m}^{2}
$$

$\begin{aligned} \text { - } \mathrm{V} \text { horizontal }(\mathrm{Vh}) & =\frac{\mathrm{Q}}{\mathrm{A} \sin \alpha} \\ \text { - Lebar flokulasi } & =1,4 \mathrm{~m}\end{aligned}$

- Panjang =1,96 $\mathrm{m}^{2} / 1,4 \mathrm{~m}=1,4 \mathrm{~m}$

- L lubang platte $=\mathrm{W} / \mathrm{sin} \alpha \quad=0,087 \mathrm{~m}$

- Jumlah platte $(\mathrm{n})=$ panjang bak / lebar total per plate $=16$ buah

- Pajang sudut platte $=1,73 / \tan 60^{\circ}$

$$
=1 \mathrm{~m}
$$

Panjang akibat sudut platte akan di manfaatkan sebagai ruang penenang aliran dan sebagai inlet bak sedimentasi untuk menambah efisiensi pengendapan di sedimentasi, dalam memanfaatkan zona tersebut panjang bak sedimentasi ditambah $30 \mathrm{~cm}$ sebagai celah antara dinding floklulasi dan platte settler. Pada zona ini arah aliran berupa downflow menuju ruang lumpur bak sedimentasi. 
Perhitungan Gutter

Direncanakan :

- Weir Loading Rate : 1,44 1/m.detik

- Debit (Q) : :3,25 1/detik

- yu gatter $\quad: 5 \mathrm{~cm}$

- Panjang gutter : panjang zona plate $=1,4 \mathrm{~m}$

- 1 gutter :2 weir

- Gutter terbuat dari plat stenlis steel

Perhitungan :

- Panjang total weir $=\mathrm{Q} / \mathrm{WLR}=2,3 \mathrm{~m}$

- Kebutuhan gutter $=1$ buah

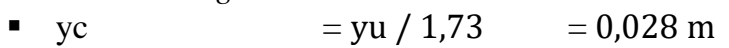

- $\operatorname{Lebar}$ gutter $(\mathrm{l})=\frac{\mathrm{Q}}{\sqrt{\mathrm{yc}^{2} \mathrm{xg}}} \quad=0,04 \mathrm{~m}$

- Kedalaman total $=7 \mathrm{~cm}$

5) Perencanaan Unit Filter

Filter yang digunakan adalah tipe rapid sand filter dengan pertimbangan rapid sand filter tidak memerlukan lahan yang luas namun membutuhkan backwash dalam pengoperasiannya. Filter ini di rencanakan menggunakan single media dengan media pasir silika. Pemilihan media pasir silika didasarkan pada kemudahan dalam mencari bahan media pasir silika dan murah. Spesifikasi media filter.

Direncanakan

- Debit (Q) : $0,0065 \mathrm{~m}^{3} /$ detik

- V filtrasi $: 5 \mathrm{~m}^{3} / \mathrm{jam} . \mathrm{m}^{2}$

- Media filter dengan media pasir silika

- Tebal media $\quad: 70 \mathrm{~cm}$

- Porositas $(\varepsilon) \quad: 0,41$

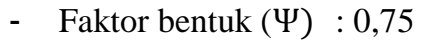

- Specific grafity $: 2,65 \mathrm{~kg} / \mathrm{m}^{3}$

- Distribusi media pasir silika dapat dilihat pada Tabel 1. Tabel 1.

Distribusi Media Pasir Silika

\begin{tabular}{cc}
\hline \hline Diameter $(\mathrm{cm})(\mathrm{d})$ & Fraksi Berat $(\mathrm{x})$ \\
\hline 0,069 & $30 \%$ \\
0,098 & $50 \%$ \\
0,130 & $20 \%$ \\
\hline \hline
\end{tabular}

- Media penyangga

- Tebal media $\quad: 20 \mathrm{~cm}$

- Porositas $(\varepsilon) \quad: 0,53$

- Faktor bentuk $(\Psi): 0,8$

- Specific grafity : $2,65 \mathrm{~kg} / \mathrm{m}^{3}$

- Distribusi media penyangga dapat dilihat pada Tabel 2. Tabel 2.

Distribusi Media Penyangga

\begin{tabular}{cc}
\hline \hline Diameter $(\mathrm{cm})$ & Fraksi Berat $(\mathrm{x})$ \\
\hline 0,4 & $100 \%$ \\
\hline \hline
\end{tabular}

- Underdrain berupa nozzle

- Slot nozzle : : $1 \mathrm{~mm}$

- Jumlah slot : 40 slot

- Tinggi slot : $15 \mathrm{~mm}$

A. Perhitungan Dimensi Unit Filter

- Jumlah bak filter ( N ) = 3 unit

- Ukuran setiap unit:

- Luas per bak (A) $=\mathrm{Q} / \mathrm{V}_{\text {filtrasi }}=1,56 \mathrm{~m}^{2}$

- $\operatorname{Lebar}(\mathrm{l}) \quad=0,9 \mathrm{~m}$
- Panjang (p) $=1,8 \mathrm{~m}$

B. Perhitungan Headloss Media

- Media pasir silika

$$
\begin{array}{lll}
-\mathrm{Nre}_{0,069 \mathrm{~cm}} & =\frac{\Psi \cdot d \cdot V_{\mathrm{f}}}{u}=0,77 \\
-\mathrm{Cd}_{0,069 \mathrm{~cm}} & =\frac{24}{\mathrm{~N}_{\mathrm{Re}}} & =31,12
\end{array}
$$

Dari perhitungan didapatkan nilai Nre dan Cd tiap diameter media yang dapat dilihat pada Tabel 3 .

Tabel 3.

\begin{tabular}{|c|c|c|c|c|}
\hline Diameter $(\mathrm{cm}$ & Fraksi Berat (X) & Nre & $\mathrm{Cd}$ & Cd.X/d \\
\hline 0,069 & $30 \%$ & 0,77 & 31,12 & 135,3 \\
\hline 0,098 & $50 \%$ & 1,10 & 25,12 & 128,2 \\
\hline 0,130 & $20 \%$ & 1,45 & 19,35 & 29,8 \\
\hline \multicolumn{4}{|c|}{ Total } & 293,2 \\
\hline
\end{tabular}

Nilai Nre dan Cd Media Pasir Silika

- Headloss $=1,067 \frac{\mathrm{L} \cdot \mathrm{V}_{\mathrm{f}}^{2}}{\Psi \cdot \varepsilon^{4} \cdot \mathrm{g}} \sum \frac{\mathrm{C}_{\mathrm{D} \cdot \mathrm{x}}}{\mathrm{d}} \quad=18,8 \mathrm{~cm}$

- Media penyangga

- Nre $_{0,13 \mathrm{~cm}}=\frac{0,75 \times 0,0004 \mathrm{~m} \times 5 \mathrm{~m} / \mathrm{s}}{0,8975 \times 10^{-6} \mathrm{~m} / \mathrm{s}}=4,47$

- $\mathrm{Cd}_{0,13 \mathrm{~cm}}=\frac{24}{\mathrm{~N}_{\mathrm{Re}}}+\frac{3}{\sqrt{\mathrm{N}_{\mathrm{Re}}}}+0,34=7,13$

- $\mathrm{Cd} . \mathrm{X} / \mathrm{d}=7,13 \times 100 \% / 0,4 \mathrm{~cm}=17,8$

- Headloss $=0,1 \mathrm{~cm}$

Headloss media total yang terjadi adalah $=18,9 \mathrm{~cm}$

C. Perhitungan Ekspansi Media

Ekspansi media sangat tergantung dengan porositas awal media kecepatan backwash. Kecepatan backwash tergantung pada diameter media penyangga sehingga pada saat backwash media penyangga tidak ikut ter ekspansi. Berikut perhitungan ekspansi media:

Kecepatan Backwash:

$\begin{aligned} \text { - Vs media penyangga } & =\sqrt{\frac{4 g(S g-1) d}{3 C_{D}}} \\ & =0,11 \mathrm{~m} / \text { detik } \\ \text { - } \mathrm{V} \text { backwash } & =V s . \epsilon^{4,5}=0,00199 \mathrm{~m} / \text { detik }\end{aligned}$

Ekspansi Media Pasir Silika

- Vs $0,069 \mathrm{~cm} \quad=0,022 \mathrm{~m} /$ detik

- $\varepsilon \mathrm{e} \quad=\left[\frac{\mathrm{vb}}{\mathrm{vs}}\right]^{0,22}=0,59$

Dari perhitungan didapatkan nilai Vs dan Ee tiap diameter media yang dapat dilihat pada Tabel 4 .

Tabel 4.

Nilai Vs dan Ee Media Pasir Silika

\begin{tabular}{ccllc}
\hline \hline Diameter $(\mathrm{cm})(\mathrm{d})$ & Fraksi Berat $(\mathrm{X})$ & $\mathrm{Vs}$ & $\mathrm{Ee}$ & $\mathrm{X} /(1-\mathrm{Ee})$ \\
\hline 0,069 & $30 \%$ & 0,022 & 0.59 & 0,732 \\
0,098 & $50 \%$ & 0,029 & 0.55 & 1,123 \\
0,130 & $20 \%$ & 0,038 & 0.52 & 0,419 \\
& Total & & & 2,274 \\
\hline \hline
\end{tabular}

- $\quad$ Tinggi ekspansi $=(1-\varepsilon) \cdot$ L. $\sum \frac{\mathrm{x}}{1-\varepsilon \mathrm{e}}=0,94 \mathrm{~m}$

Cek Ekspansi Media Penyangga

- $\varepsilon e \quad=0,41$

- $\mathrm{X} /(1-\mathrm{Ee}) \quad=1,706$

- Tinggi ekspansi $=0,20 \mathrm{~m}$

- Ekspansi total $=1,14 \mathrm{~m}$

- $\%$ ekspansi $=\frac{\mathrm{T}_{\text {total }}-\mathrm{T}_{\text {media }}}{\mathrm{T}_{\text {media }}} \times 100 \%=26,7 \%$ 
Kehilangan Tekanan Awal Backwash

- Hf silika $=(S e-1)(1-\varepsilon) \times L=0,68 \mathrm{~m}$

- Hf penyangga $=0,16 \mathrm{~m}$

- Hf total $=0,84 \mathrm{~m}$

-

D. Perhitungan Nozzle Filter

Direncanakan:

- Kecepatan aliran : $0,2 \mathrm{~m} /$ detik

- Konstanta friksi : 0,8

- Debit filtrasi : $0,00163 \mathrm{~m}^{3} / \mathrm{detik}$

- Debit backwash : 0,00207 $\mathrm{m}^{3} / \mathrm{detik}$

Perhitungan:

- Luas slot nozzle $=600 \mathrm{~mm}^{2} /$ nozzle

- Q per nozzle $=0,00012 \mathrm{~m}^{3} /$ detik

- Jumlah nozzle $=Q$ backwash $/ Q$ nozzle $=27$ buah

- Cek kecepatan aliran di nozzle

Q filtrasi $\quad=0,13 \mathrm{~m} /$ detik

$\mathrm{Q}$ backwash $=0,2 \mathrm{~m} /$ detik

- Headloss pada nozzle

Filtrasi $\quad=\mathrm{Kx} \frac{\mathrm{v}^{2}}{2 \mathrm{~g}} \quad=0,0059 \mathrm{~m}$

Backwash $=0,0087 \mathrm{~m}$

E. Headloss Total pada Filter

- Hf fitrasi = Hf media + Hf nozzle $=18,96 \mathrm{~cm}$

- Hf backwash $=84,09 \mathrm{~cm}$

\section{F. Perhitungan Gutter}

Gutter ini merupakan saluran pelimpah untuk menerima air bachwash dan melimpahkan air menuju media filter. Perencanaan gutter sebagai berikut:

Direncanakan:

- Jumlah gutter : 1 buah

- Debit tiap filter : 0,00323 $\mathrm{m}^{3} / \mathrm{detik}$ (debit backwash)

- Panjang gutter : Panjang filter 1,8 m

- Kedalaman air (yu) : 0,05 m

Perhitungan:

- Lebar gutter $\quad=0,04 \mathrm{~m}$

- Tinggi lokasi gutter $\quad=1,34 \mathrm{~m}$

G. Perhitungan Pompa Backwash

Pompa backwash direncanakan menggunakan pompa sentrifugal sejumlah dua unit yang berkerja secara bergantian. Air yang digunakan untuk proses backwash adalah air hasil olahan yang belum di injeksi desinfektan. Penggunaan air ini bertujuan agar komponen biologis dalam media filter tidak mati sehingga proses filtrasi akan berlangsung secara optimal.

Direncanakan:

- Debit backwash :0,00323 $\mathrm{m}^{3} / \mathrm{detik}$

- Panjang pipa backwash : $17 \mathrm{~m}$

- Headloss backwash : :84,09 cm

Perhitungan

Digunakan pipa di pasaran berdiameter $62,5 \mathrm{~mm}(2,5$ inch $)$

- Hf pipa $=0,45 \mathrm{~m}$

Berdasarkan kebutuhan sistem spesifikasi pompa yang dibutuhkan dengan $\mathrm{Q}=5,2 \mathrm{l} / \mathrm{detik} \mathrm{H}=5,8 \mathrm{~m}$
Dari unit koagulasi, flokulasi, sedimentasi dan filter didesain menjadi 1 unit bangunan. Desain unit IPA dapat dilihat pada Gambar 3 dan Gambar 4.

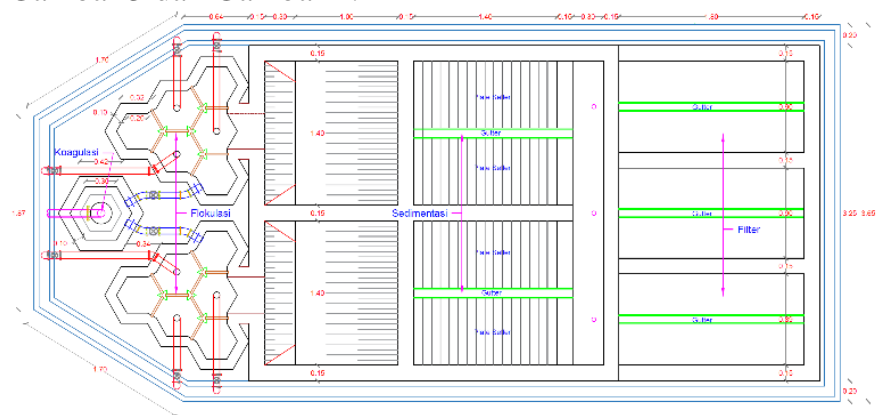

Gambar 3. Layout Unit IPAM

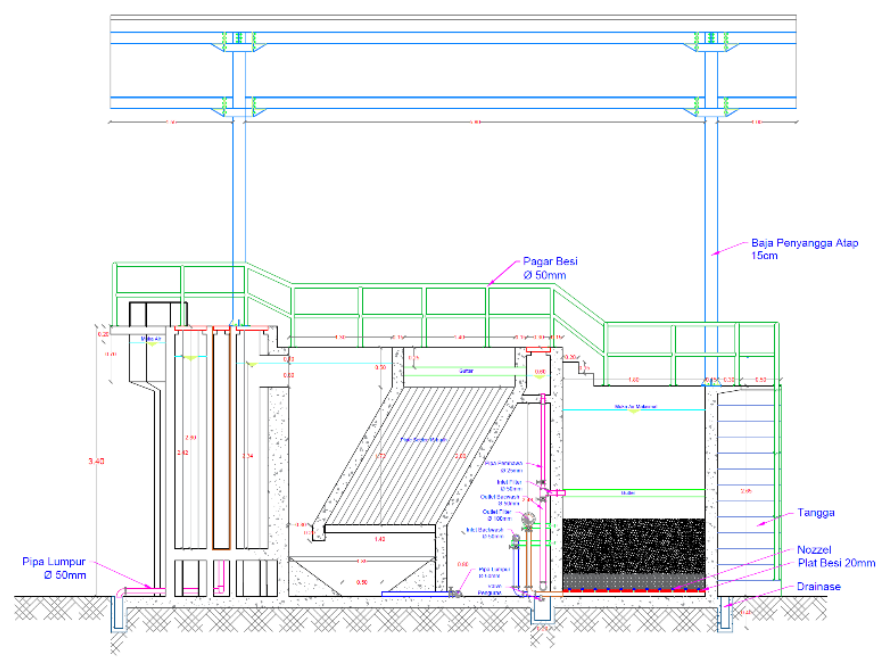

Gambar 4. Desain Unit IPA

\section{6) Perencanaan Unit Reservoir}

Reservoir berfungsi sebagai penampung air hasil olahan karena debit air olahan yang linier sedangkan debit kebutuhan air yang fluktuasi. Unit pengolahan air ITS ini hanya di tujukan untuk kegiatan akademik dalam Kampus maka perhitungan reservoir digunakan jam kerja Kampus, dianggap di luar jam kerja kebutuhan air yang jauh menurun atau hampir tidak ada maka selama itu tersebut air produksi akan disimpan di reservoir. Kampus ITS memiliki jam kerja efektif dari jam 06.00 sampai 20.00 atau selama 14 jam. Pada perencanaan ini di gunakan lama aktivitas Kampus selama 12 jam dikarenakan untuk faktor keamanan.

\section{A. Dimensi Reservoir}

Direncanakan:

- Waktu aktivitas Kampus ( $\left.\mathrm{T}_{\text {Kampus }}\right) \quad: 12 \mathrm{jam} / \mathrm{hari}$

- Waktu produksi IPAM $\left(\mathrm{T}_{\text {IPAM }}\right) \quad: 24 \mathrm{jam} / \mathrm{hari}$

- Debit produksi $\left(\mathrm{Q}_{\mathrm{p}}\right) \quad: 6,5 \mathrm{l}$ /detik

- Kedalaman reservoir (h) $\quad: 2,5 \mathrm{~m}$

- Lebar reservoir (1) :7 m

- Jarak antar baffle : $\quad: 2,5 \mathrm{~m}$

Perhitungan:

- Volume reservoir $=\left(\mathrm{T}_{\text {IPAM }}-\mathrm{T}_{\text {KAMPUS }}\right) \mathrm{xQ}_{\mathrm{p}}=280,8 \mathrm{~m}^{3}$

- Panjang reservoir $=16,1 \mathrm{~m}$ 


\section{B. Rumah Pompa}

Pendistribusian air hasil olahan mencangkup wilayah Kampus ITS sehingga head pompa yang dibutuhkan tidak terlalu besar, head sistem distribusi eksisting sebesar $25 \mathrm{~m}$, maka pompa distribusi direncanakan dengan head maksimum pompa $30 \mathrm{~m}$. Area Kampus memiliki fluktuasi penggunaan air yang sangat cukup tinggi pada waktu jam efektif bisa mencapai 2 kali dari kebutuhan dan pada waktu malam hari memiliki kebutuhan air yang kecil karena tidak terdapat kegiatan dalam Kampus. Dengan fluktuasi kebutuhan yang tinggi maka dipilih jenis pompa sentrifugal dengan tipe variable speed dan debit 15 1/detik. Pompa yang digunakan sebanyak dua unit yang akan bekerja secara bergantian. Menggunakan pompa variabele speed akan memperkecil biaya operasi di karena debit yang di pompa dapat di atur secara otomatis mengikuti kebutuhan air dan head yang di berikan relatif konstan. Desain unit reservoir dan rumah pompa dapat dilihat pada Gambar 5.

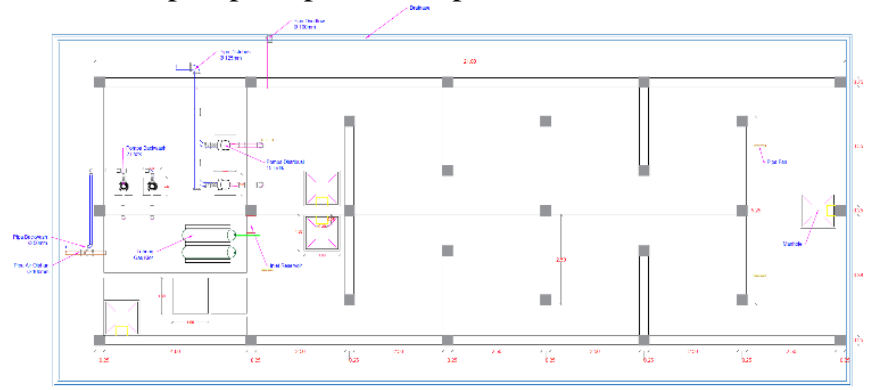

Gambar 5. Desain Unit Reservoir dan Rumah Pompa

\section{Utilitas Lantai 2 Reservoir}

Unit reservoir memiliki lahan yang luas sehingga ditambahkan bangunan di atas reservoir tanpa mengganggu sistem. Penambahan bangunan berupa ruang klor, koagulan, laboratorium, ruang kontrol, gudang, ruang pegawai. Desain utilitas reservoir lantai 2 dapat di lihat pada Gambar 6 dan Layout IPAM Kampus ITS dapat dilihat pada Gambar 7.

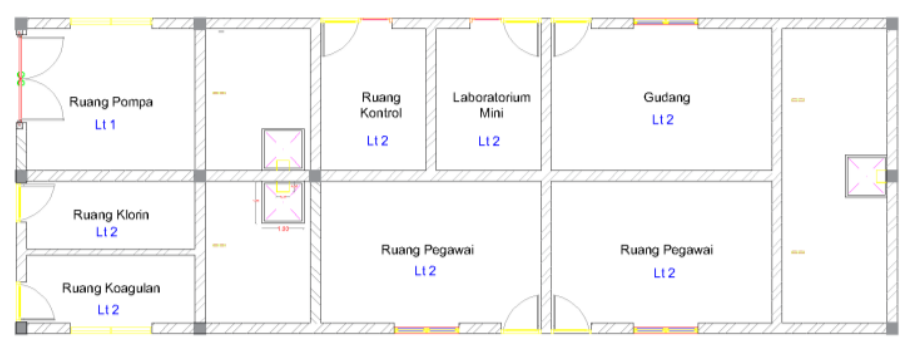

Gambar 6. Desain Utilitas Lantai 2 Reservoir dan Rumah Pompa

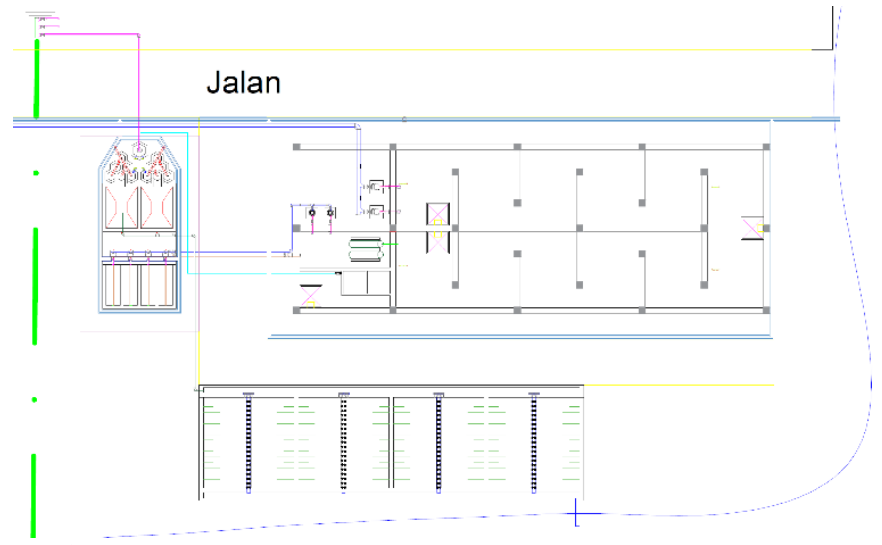

Gambar 7. Layout IPAM Kampus ITS

\section{KESIMPULAN}

1. Kampus ITS memiliki potensi dalam pemanfaatan limpasan air hujan untuk memenuhi kebutuhan air minum Kampus ITS dengan kualitas memenuhi standar air baku kelas 2 .

2. Unit pengolahan yang digunakan adalah intake, koagulasi, flokulasi, sedimentasi, filtrasi, desinfeksi, reservoir dan rumah pompa.

3. Pembangunan unit pengolahan air minum Kampus ITS dapat menghemat anggaran biaya untuk penyediaan air minum Kampus ITS

\section{DAFTAR PUSTAKA}

[1] Biro Akademik dan Kemahasiswaan (BAAK). 2016. Jumlah Mahasiswa Kampus ITS 2006-2015. Surabaya: Administrasi Institut Teknologi Sepuluh Nopember

[2] Biro Administrasi Umum dan Keuangan (BAUK). 2016. Jumlah Tenaga Pendidik Kampus ITS 2006-2015. Surabaya: Administrasi Institut Teknologi Sepuluh Nopember.

[3] Badan Meteorologi Klimatologi dan Geofisika. 2016. Data Tinggi Hujan Kota Surabaya. Surabaya: Pemerintah Kota Surabaya

[4] Biro Perencanaan Kampus. 2016. Masterplan ITS. Surabaya: Perencanaan Kampus ITS.

[5] Menteri Kesehatan Republik Indonesia. 2010. Peraturan Menteri Kesehatan Republik Indonesia Nomor 492/MenKes/Per/IV/2010 Tentang Syarat-syarat dan Pengawas Kualitas Air Minum

[6] Kawamura, Susumu. 1991. Integrated Design of Water Treatment Facilities. New York: John Wiley \& Sons, Inc

[7] Masduqi, A., Assomadi, A.F. 2012. Operasi dan Proses Pengolahan Air. Surabaya: ITS Press. 